\title{
Aproveitamento agroindustrial de resíduos sólidos provenientes do melão minimamente processado
}

\author{
Agroindustrial use for the solids wastes deriving from minimally processed melon
}

\author{
Ana Carolina Almeida MIGUEL ${ }^{1 *}$, Silvana ALBERTINI ${ }^{1}$, Gabriela Fernandes BEGIATO ${ }^{1}$, \\ João Ricardo Pecini Stein DIAS ${ }^{1}$, Marta Helena Fillet SPOTO ${ }^{1}$
}

\begin{abstract}
Resumo
Um dos principais entraves ao desenvolvimento da indústria de processamento mínimo de frutas e hortaliças em diversas partes do mundo está associado à significativa quantidade de resíduos orgânicos que são gerados pela atividade. Em vista disso, este trabalho teve como objetivo estudar alternativas para o aproveitamento das cascas e das sobras de polpa de melões minimamente processados. Da casca foram desenvolvidos três produtos, compota, doce e doce glaceado; e com as sobras de polpa foram elaboradas geléias. Os produtos elaborados foram avaliados quanto à composição centesimal e sensorialmente, usando escala hedônica de 9 pontos, e contou com a participação de 30 provadores não treinados. Através dos resultados, constatou-se que os produtos obtidos a partir da casca apresentaram maiores teores de cinzas, proteína e fibra alimentar. O teste sensorial indicou que todos os produtos elaborados, com exceção do doce, obtiveram aceitabilidade por parte dos julgadores, com índices superiores a $80 \%$.
\end{abstract}

Palavras-chave: Cucumis melo; indústria de alimentos; polpa; análise sensorial.

\begin{abstract}
One of the main impediments to the development of the minimally processed industry of fruits and vegetables in diverse parts of the world is associated with the significant amount of organic residues that are generated by the activity. Then, this work proposed to study alternatives for the exploitation of the peels and the pulp's leftovers of minimally processed melons. Of the peels three products were developed, compote, candy and icing candy; and with the pulp's leftovers was elaborated jellies. The products were evaluated about centesimal composition and sensorially, using hedonic scale of nine points, and counted with participation of thirty non-trained panelists. The results showed that the products made with the peels presented larger contents of ashes, protein and alimentary fiber. The sensorial test indicated that all the elaborated products, except the candy, showed acceptability for panelists, with rates above of $80 \%$.

Keywords: Cucumis melo; food industry; pulp; sensory analysis.
\end{abstract}

\section{Introdução}

Um dos principais entraves ao desenvolvimento da indústria de processamento mínimo de frutas e hortaliças em diversas partes do mundo está associado à significativa quantidade de resíduos orgânicos que são gerados pela atividade. Em muitos casos, como no processamento mínimo de melões, o rendimento é da ordem de 38 a $42 \%$ em massa fresca dos frutos inteiros (PINTO, 2002), isto é, de 58 a $62 \%$ da matéria-prima é descartada como resíduo.

O melão é um dos hortigranjeiros que tem sido minimamente processado no Brasil nas mais diversas formas: em formato de bolinhas, fatias e cubos com ou sem casca (LUNA-GUSMÁN; CANTWELL; BARRET, 1999). Para a agroindústria, o retorno desse tipo de processamento é alto, pois eles apresentam uma grande capacidade de agregação de valor.

Infelizmente, ainda existem poucas alternativas para a utilização da maior parte dos resíduos vegetais, sendo esses dispostos no ambiente, utilizados como fertilizantes orgânicos ou na alimentação animal, sem qualquer tratamento. Porém, a demanda por ração pode variar e depender da produção agrícola, além do problema de descarte desses subprodutos, agravado por restrições legais (LAUFENBERG; KUNZ; NYSTROEM, 2003; SCHIEBER; STINTZING; CARLE, 2001).

A composição dos resíduos do processamento de alimentos é extremamente variada e depende tanto da natureza da matériaprima como da técnica de produção empregada (MORETTI; MACHADO, 2006). Os principais resíduos do processamento de melão são casca, sementes e sobras dos cortes.

As cascas são constituídas basicamente por carboidratos, proteínas e pectinas, o que possibilitaria seu aproveitamento para fabricação de doces, podendo-se tornar uma alternativa viável para resolver o problema da eliminação dos resíduos, além de aumentar seu valor comercial.

Recebido para publicação em 28/10/2007

Aceito para publicação em 14/1/2008 (002966)

${ }^{1}$ Departamento de Agroindústria, Alimentos e Nutrição, Escola Superior de Agricultura "Luiz de Queiroz" - ESALQ, Av. Pádua Dias, 11, CP 9, CEP 13418-900,

Piracicaba - SP, Brasil, E-mail: acmiguel@esalq.usp.br

${ }^{*}$ A quem a correspondência deve ser enviada 
As sementes constituem uma parte significativa dos resíduos gerados no processamento do melão, podendo ser consumidas como petiscos a exemplo das sementes de abóbora, as quais necessitam, para o seu processamento, apenas de uma secagem e tempero com sal (MORETTI; MACHADO, 2006).

Num mundo globalizado, onde parte significativa da população encontra sérias dificuldades diariamente para conseguir alimento, é inconcebível que uma atividade agroindustrial continue desperdiçando um resíduo que potencialmente poderia ser utilizado como matéria-prima na indústria de alimentos (MORETTI; MACHADO, 2006).

Partiu-se da hipótese de que o uso destes resíduos na alimentação humana possa tornar mais viável a atividade de processamento mínimo. Estudaram-se alternativas para o aproveitamento das cascas e dos resíduos de polpa de melões minimamente processados.

\section{Material e métodos}

\subsection{Matéria-prima}

Para a elaboração dos produtos, realizada na Planta Piloto de Processamento do Departamento de Agroindústria, Alimentos e Nutrição da ESALQ/USP, foram utilizadas cascas e sobras de polpa do processamento mínimo de 20 melões 'Amarelo' (oriundos da região de Mossoró/RN). Foram também utilizados açúcar refinado e condimento à base de cravo adquiridos no comércio local de Piracicaba, SP.

Da casca foram desenvolvidos três produtos, compota, doce e doce glaceado; e com os resíduos de polpa foram elaboradas geléias.

\subsection{Métodos}

\section{Processo de elaboração da compota}

As cascas, obtidas após a separação da polpa durante o processamento mínimo, foram lavadas em água corrente, imersas em solução de dicloroisocianurato de sódio dihidratado a $100 \mathrm{ppm}$ por 10 minutos, com o objetivo de reduzir os riscos de contaminação e drenadas por aproximadamente três minutos em escorredor doméstico, devidamente higienizado.

As cascas foram cortadas em pedaços uniformes e previamente cozidas em xarope ( $\left.10^{\circ} \mathrm{Brix}\right)$ até que ficassem transparentes, antes de serem embaladas. Em seguida, procedeu-se ao enchimento manual das embalagens de vidro, previamente esterilizadas a $100{ }^{\circ} \mathrm{C} / 30$ minutos, com capacidade para $250 \mathrm{~g}$ e fechadas com tampa de metal. Às cascas de melão acondicionadas nos vidros, foi adicionada calda de açúcar $\left(85^{\circ} \mathrm{C}\right)$ na concentração de $30^{\circ}$ Brix até cobrir todo o produto. A exaustão foi feita em banho-maria a $100{ }^{\circ} \mathrm{C}$ por 10 minutos, com as embalagens semitampadas, até completa remoção do ar. Em seguida, os frascos foram fechados e resfriados até atingir a temperatura de $38-40{ }^{\circ} \mathrm{C}$. Posteriormente, os produtos foram lacrados e armazenados à temperatura ambiente.

\section{Processo de elaboração do doce}

As cascas, obtidas após a separação da polpa durante o processamento mínimo, foram submetidas aos processos de lavagem e sanificação dos melões, segundo descrito no item anterior.

Para a obtenção dos doces, foi utilizado um processo tradicional, segundo Jackix (1988). As cascas foram cortadas em pedaços uniformes e adicionadas em calda a $65^{\circ} \mathrm{Brix}$, na qual sofreram cocção por aproximadamente 1 hora e 30 minutos a $90{ }^{\circ} \mathrm{C}$, até que ficassem transparentes. Ao final, os produtos foram acondicionados a quente $\left(85^{\circ} \mathrm{C}\right)$ em embalagens de vidro, previamente esterilizadas a $100^{\circ} \mathrm{C} / 30$ minutos, com capacidade para $250 \mathrm{~g}$ e fechadas com tampa de metal. O tratamento térmico foi efetuado em banho-maria a $100{ }^{\circ} \mathrm{C}$ por 15 minutos. Em seguida, os frascos foram invertidos para promover a esterilização das tampas por 15 minutos, resfriados à temperatura ambiente, lacrados e, posteriormente, armazenados na mesma temperatura.

\section{Processo de elaboração do doce glaceado}

As cascas, obtidas após a separação da polpa durante o processamento mínimo, foram submetidas aos processos de lavagem e sanificação dos melões, como descrito no item anterior.

As cascas foram cortadas em tiras e previamente cozidas em xarope $\left(30^{\circ} \mathrm{Brix}\right)$ até que ficassem transparentes. Iniciouse a operação de açucaramento mergulhando-se os pedaços em xarope de açúcar a concentrações crescentes até atingir a concentração de $75^{\circ}$ Brix. Após a impregnação do produto com açúcar, este foi retirado do xarope e colocado numa peneira para a retirada do excesso de açúcar. Por fim, procedeu-se à secagem em estufa a $40^{\circ} \mathrm{C}$ até obter-se uma umidade final inferior a $25 \%$, sendo, então, o produto espalhado em bandejas perfuradas.

As cascas de melão glaceadas foram acondicionadas em sacos de polipropileno $(\mathrm{PP})(18 \times 25 \times 0,05 \mathrm{~cm})$. Cada embalagem, contendo aproximadamente $100 \mathrm{~g}$ de produto, foi selada em seladora manual e armazenada à temperatura ambiente.

\section{Processo de elaboração de geléia}

As sobras de polpa resultantes do processamento mínimo de melão foram imersas em solução de dicloroisocianurato de sódio dihidratado a $100 \mathrm{ppm}$ por três segundos, com o objetivo de reduzir os riscos de contaminação, e drenadas por aproximadamente três minutos em escorredor doméstico, devidamente higienizado. Os pedaços de melão foram fervidos à pressão atmosférica em tacho aberto até a obtenção do suco, que, posteriormente, foi filtrado com o auxílio de peneiras de 35 mesh.

Aos pedaços de melão, foram adicionados sacarose $(0,75: 1 \mathrm{p} / \mathrm{p}$ em relação à massa total dos frutos) e pectina com $150{ }^{\circ} \mathrm{SAG}$ (quantidade calculada com base no ${ }^{\circ} \mathrm{SAG}$ e peso de sacarose).

A formulação foi preparada com a concentração final de sólidos solúveis de $68^{\circ} \mathrm{Brix}$. Os produtos foram acondicionados a quente $\left(85^{\circ} \mathrm{C}\right) \mathrm{em}$ embalagens de vidro, previamente esterilizadas a $100^{\circ} \mathrm{C} / 30$ minutos, com capacidade para $250 \mathrm{~g}$ e fechadas com tampa de metal. $\mathrm{O}$ tratamento térmico foi efetuado em 
banho-maria a $100{ }^{\circ} \mathrm{C}$ por 15 minutos. Em seguida, os frascos foram invertidos para promover a esterilização das tampas por 15 minutos, resfriados à temperatura ambiente, lacrados e, posteriormente, armazenados à temperatura ambiente.

\subsection{Caracterização dos produtos}

As amostras de compota, de doce e de doce glaceado foram dispostas em placas de petri e secas em estufa a $50{ }^{\circ} \mathrm{C}$. Após a secagem, os materiais foram moídos em moinho TE 650 (Moinho de facas) tipo Willye, utilizando peneira de aço inox-malha 20, e submetidos à avaliação centesimal.

A composição centesimal da compota, do doce e de melão glaceado foi feita com base na matéria seca, sendo os resultados convertidos para matéria úmida; enquanto que para a geléia, todas as determinações foram feitas com base na matéria úmida.

Para a caracterização dos produtos elaborados a partir dos resíduos do processamento, foram realizadas as seguintes análises, em triplicata: umidade: determinada por secagem em estufa a $50{ }^{\circ} \mathrm{C}$ com circulação de ar até obtenção de peso constante, segundo procedimento da AOAC (1997); cinzas (\%): determinada através da incineração das amostras em mufla à temperatura de $500-600{ }^{\circ} \mathrm{C}$ por 4 horas AOAC (1997); proteínas (\%): foi determinada pelo método de Kjeldahl, sendo o teor protéico determinado pela multiplicação do conteúdo de nitrogênio total pelo fator de 6,25 AOAC (1997); extrato etéreo (\%): foi determinado utilizando-se o extrator de Sohxlet. Na extração, foi utilizado como solvente o hexano em refluxo contínuo da amostra durante 8 horas. Recuperado o hexano, os balões foram retidos e colocados em estufa por 30 minutos a $100{ }^{\circ} \mathrm{C}$, depois disso, esfriaram em dessecador e foram pesados, obtendo-se a quantidade de lipídios por diferença de peso do balão AOAC (1997); fibra alimentar total: determinada pelo método nãoenzímico gravimétrico para alimentos com reduzido teor de amido, segundo Li e Cardozo (1992); Carboidratos: foram obtidos por diferença, ou seja, 100 - (\% umidade $+\%$ proteína + $\%$ cinzas $+\%$ extrato etéreo $+\%$ fibra bruta).

Calculou-se também o valor calórico total dos produtos elaborados aplicando-se os valores de conversão para carboidratos (4,0 kcal), lipídios (9,0 kcal) e proteína (4,0 kcal), de acordo com o indicado pelo Instituto Adolfo Lutz (1985).

\section{Análise sensorial}

Os produtos elaborados a partir do resíduo do processamento mínimo do melão foram avaliados quanto à aceitação em laboratório. O teste realizou-se no Laboratório de Análise Sensorial do Departamento de Agroindústria, Alimentos e Nutrição, da ESALQ/USP e contou com a participação de trinta voluntários não treinados, compostos por estudantes, funcionários e professores do Departamento de Agroindústria, Alimentos e Nutrição da ESALQ/USP.

Os provadores avaliaram as amostras em cabines individualizadas. Cada provador recebeu 4 amostras devidamente codificadas, cada uma contendo aproximadamente $30 \mathrm{~g}$ de produto, juntamente com a ficha de avaliação e bolacha de água e sal para ser consumida entre as avaliações. Cada amostra foi composta por doce de casca de melão, compota de casca de melão, geléia de melão e melão glaceado.

Os provadores foram solicitados a indicar o quanto gostaram/desgostaram utilizando-se de escala hedônica de 9 pontos ( 1 = desgostei muitíssimo; 2 = desgostei muito; 3 = desgostei moderadamente; 4 = desgostei ligeiramente; 5 = nem gostei/ nem desgostei; 6 = gostei ligeiramente; 7 = gostei moderadamente; 8 = gostei muito; 9 = gostei muitíssimo) e o que mais gostaram/desgostaram em cada produto.

\subsection{Análise dos resultados}

No teste de aceitabilidade em laboratório, o delineamento experimental utilizado foi em blocos inteiramente casualizados dos quatro produtos elaborados a partir dos resíduos do processamento mínimo com 30 repetições (provadores).

O delineamento experimental utilizado para avaliação dos resultados obtidos da caracterização dos produtos foi em blocos inteiramente casualizados, com três repetições, e constituído de 4 produtos, sendo: compota, doce, melão glaceado e geléia.

Os resultados obtidos foram submetidos à análise de variância pelo teste $F$ e a comparação das médias pelo Teste de Tukey (5\%), de acordo com o proposto por Gomes (2002).

\section{Resultados e discussão}

\subsection{Caracterização dos produtos}

A Tabela 1 contém os resultados da composição centesimal dos produtos elaborados a partir dos resíduos do processamento do melão. A compota apresentou um teor de umidade significativamente superior aos demais produtos, o que já era esperado uma vez que este tipo de alimento é conservado em calda, implicando em maior umidade. Este resultado pode ser explicado pelo fato do xarope conter elevada concentração de açúcares, porém atividade de água relativamente superior à da casca. Em contato com elas, com atividade de água inferior, a diferença de pressão osmótica produz a passagem de água do xarope para a casca, provocando um aumento no teor de umidade (BOBBIO; BOBBIO, 2001). O melão glaceado foi o que apresentou menor teor de umidade; conseqüência do processo de elaboração do produto, haja vista que é submetido à secagem, o que faz com que sua umidade seja reduzida.

Os teores médios de cinzas dos produtos apresentaram diferenças significativas entre si, como consta na Tabela 1. A compota foi a que apresentou o maior teor de cinzas, seguido do glaceado de melão, do doce e da geléia. Entretanto, a casca apresentou um teor de cinzas de $0,98 \%$ e a polpa de $0,45 \%$.

De acordo com pesquisas realizadas pela USDA (1999), o teor de cinzas em polpa de melão é de $0,3 \%$, enquanto que Gondim et al. (2005) encontraram na polpa um teor de cinzas de $0,5 \%$ e na casca de $0,96 \%$.

Levando-se em consideração os teores citados acima, pode-se afirmar que os valores encontrados neste trabalho estão próximos aos obtidos pelos autores supracitados e confirmam o predomínio de cinzas na casca. 
Com relação aos teores médios da fração protéica apresentados nos produtos, constatou-se que aqueles elaborados da casca apresentaram teores superiores à geléia (Tabela 1) obtida da polpa, indicando que as proteínas apresentam maior contribuição na composição química da casca.

Os teores de proteína encontrados para a polpa de melão 'Amarelo' apresentados por vários autores, entre eles USDA (1999) e Gondim et al. (2005), encontram-se na faixa de 0,4 a $1 \%$. As cascas de melão apresentam teores de proteína de aproximadamente 1,24\% (GONDIM et al., 2005).

As principais fontes protéicas de origem vegetal são, segundo Fennema (1993), a soja (45\%), o trigo (14\%) e a aveia (13\%), que se mostram com teores superiores aos das partes do melão analisadas. Esta superioridade já era de se esperar, uma vez que os frutos são considerados fontes pobres em proteínas, sendo mais ricos em fibras, vitaminas e minerais.

Os teores de extrato etéreo apresentados pelos produtos elaborados a partir da casca e da polpa não apresentaram diferenças significativas, tendo a casca apresentado teores médios de $0,12 \%$ e a polpa de $0,07 \%$ (Tabela 1 ).

A USDA (1999) encontrou um teor de lipídios de 0,2\% na polpa do fruto do melão. Gondim et al. (2005) não detectaram presença de lipídios para a polpa do melão, enquanto que, para a casca, obtiveram valores médios de lipídios de 0,10\%.

Com base nos resultados obtidos, pode-se dizer que a polpa e a casca do melão não são consideradas fontes de óleo, por apresentarem baixos teores de extrato etéreo.

Os carboidratos, juntamente com as proteínas, formam os constituintes principais dos organismos vivos, além de serem a mais abundante e econômica fonte de energia para o homem (BOBBIO; BOBBIO, 2003). O teor de carboidratos encontrado na compota revelou-se inferior $(35,50 \%)$ aos demais produtos, o que já era esperado, dada a menor adição de açúcar, aliada ao maior teor de umidade característico deste tipo de produto (Tabela 1). Em contrapartida, o produto glaceado foi o que apresentou a maior contribuição dos carboidratos na sua composição, o que é resultado do elevado teor de açúcar e do baixo teor de umidade do produto, refletindo no elevado valor calórico apresentado.

Em relação aos teores de fibra alimentar (Tabela 1) encontrados nos produtos elaborados das partes do melão, a casca apresentou valores médios estatisticamente superiores aos da polpa, com teores de 2,97 e 0,58\%, respectivamente.

As fibras alimentares, de acordo com Thebaudin et al. (1997), desempenham um papel importantíssimo no aumento do volume do bolo fecal e no tempo de trânsito gastrintestinal, sendo importantes sob o aspecto da prevenção de câncer no intestino grosso e cólon, uma vez que permanecem com compostos 'cancerígenos' presentes nas fezes, oriundos de diferentes fontes, e que poderiam atuar ou não, em função do tempo de sua retenção no organismo.

De acordo com a Tabela de Composição de Alimentos (2007) e Gondim et al. (2005), o teor de fibra da polpa do melão está na faixa de 0,03 a $0,3 \%$. Gondim et al. (2005) constataram que a casca do melão apresenta teor de fibras de 1,42\%.

Segundo Brasil (2007), um alimento com teor de 2 a 3\% de fibra alimentar pode ser considerado uma boa fonte de fibra. Com base nos resultados obtidos, pode-se dizer que os produtos obtidos da casca do melão são boa fonte de fibra.

\subsection{Análise sensorial}

O teste de aceitabilidade, realizado com os produtos obtidos a partir dos resíduos do processamento mínimo do melão, revelou diferença significativa entre as amostras (Tabela 2). Comparando os valores médios da escala hedônica, observa-se que a geléia, a compota e o melão glaceado não diferiram entre si quanto ao grau de aceitação e, ao mesmo tempo, foram os que apresentaram maior aceitação nas condições deste trabalho. Na escala hedônica de 9 pontos, o doce de melão apresentou valor médio de 5,77, situado entre os termos "nem gostei/nem desgostei" e "gostei ligeiramente".

De acordo com Dutcoksky (1996), para que um produto seja considerado aceito, em termos de suas propriedades sensoriais, é necessário que se obtenha um índice mínimo de aceitabilidade de $70 \%$, e, neste caso, todos os produtos elaborados, com exceção do doce de melão, obtiveram boa aceitabilidade por parte dos provadores (Figura 1).

Tabela 2. Aceitabilidade dos produtos obtidos a partir dos resíduos do processamento mínimo de melão.

\begin{tabular}{lc}
\hline Produtos & Notas $^{\star}$ \\
\hline Geléia & $7,47^{\mathrm{a}}$ \\
Doce & $5,77^{\mathrm{b}}$ \\
Compota & $7,73^{\mathrm{a}}$ \\
Melão glaceado & $7,30^{\mathrm{a}}$ \\
CV (\%) & 21,06 \\
\hline
\end{tabular}

${ }^{*} 1$ = desgostei muitíssimo; 2 = desgostei muito; 3 = desgostei moderadamente; 4 = desgostei ligeiramente; 5 = nem gostei/nem desgostei; 6 = gostei ligeiramente; 7 = gostei moderadamente; 8 = gostei muito; e 9 = gostei muitíssimo. Médias seguidas de pelo menos uma letra comum na coluna não diferem significativamente entre si pelo teste de Tukey $(\mathrm{p}<0,05)$.

Tabela 1. Caracterização de produtos obtidos a partir de resíduos do processamento mínimo de melão.

\begin{tabular}{|c|c|c|c|c|c|c|c|}
\hline \multirow[t]{2}{*}{ Produtos } & \multicolumn{6}{|c|}{ Composição centesimal (\%) } & \multirow{2}{*}{$\begin{array}{l}\text { Valor calórico } \\
\left(\mathrm{kcal} .100 \mathrm{~g}^{-1}\right)\end{array}$} \\
\hline & Umidade & Cinzas & Proteína & Extrato etéreo & Fibra alimentar & Carboidratos & \\
\hline Doce & $31,49^{\mathrm{b}}$ & $0,84^{c}$ & $1,63^{\mathrm{a}}$ & $0,06^{\mathrm{a}}$ & $2,94^{\mathrm{ab}}$ & $61,85^{c}$ & $260,11^{\mathrm{c}}$ \\
\hline Compota & $56,88^{a}$ & $1,16^{\mathrm{a}}$ & $2,18^{\mathrm{a}}$ & $0,14^{\mathrm{a}}$ & $1,83^{\mathrm{bc}}$ & $35,50^{\mathrm{d}}$ & $154,93^{\mathrm{d}}$ \\
\hline Glaceado & $12,98^{\mathrm{c}}$ & $0,96^{\mathrm{b}}$ & $2,18^{\mathrm{a}}$ & $0,16^{\mathrm{a}}$ & $4,15^{\mathrm{a}}$ & $78,76^{\mathrm{a}}$ & $328,26^{\mathrm{a}}$ \\
\hline Geléia & $29,78^{\mathrm{b}}$ & $0,45^{\mathrm{d}}$ & $0,80^{\mathrm{b}}$ & $0,07^{\mathrm{a}}$ & $0,58^{\mathrm{c}}$ & $68,87^{\mathrm{b}}$ & $277,23^{\mathrm{b}}$ \\
\hline $\mathrm{CV}(\%)$ & 55,23 & 2,57 & 17,56 & 39,58 & 16,23 & 1,87 & 1,55 \\
\hline
\end{tabular}

Obs.: médias seguidas de pelo menos uma letra comum na coluna não diferem significativamente entre si pelo teste de Tukey (p <0,05). 


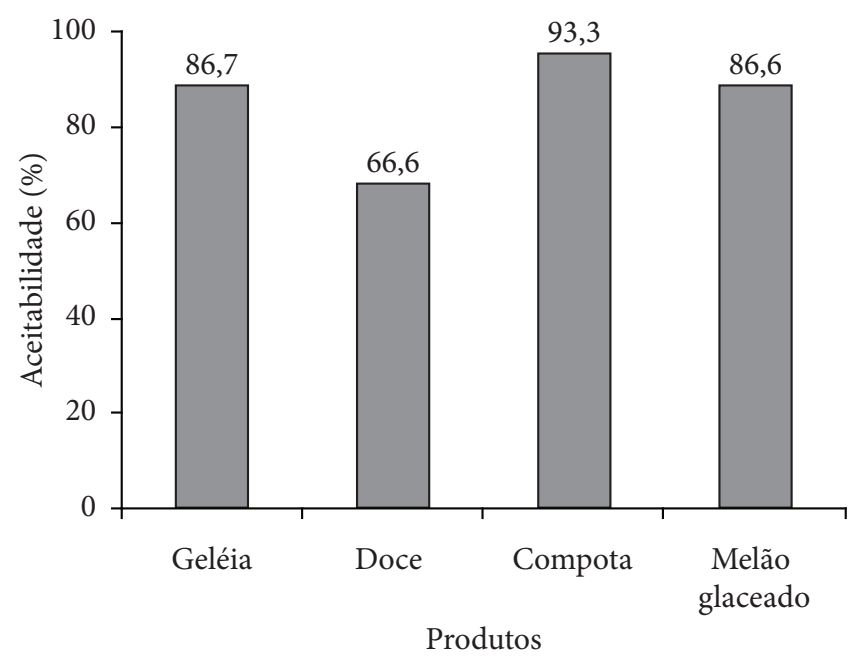

Figura 1. Relação entre a percentagem de aceitabilidade por produto elaborado a partir dos resíduos do processamento mínimo de melão.

No que se refere aos comentários sobre os produtos, os provadores destacaram na geléia, na compota e no melão glaceado, o sabor e a textura agradáveis e no doce, o sabor muito doce/ muito açucarado, o sabor residual e a textura desagradável.

\section{Conclusões}

- Produtos obtidos a partir de resíduos da casca de melão apresentaram maiores teores de cinzas, proteína e fibra alimentar, em relação aos obtidos do resíduo da polpa; e

- A casca e o resíduo da polpa de melão minimamente processado constituem matéria-prima para a elaboração de compota, doce glaceado e geléia, aceitáveis sensorialmente por consumidores.

\section{Agradecimentos} autora.

Ao $\mathrm{CNPq}$ pela bolsa de mestrado concedida à primeira

\section{Referências bibliográficas}

AOAC - ASSOCIATION OF OFFICIAL ANALITICAL CHEMISTRY. Official methods of analysis of the Association of Analytical Chemists International. 16 ed. Washington: AOAC, 1997. p. $2-45$.

BOBBIO, F. O.; BOBBIO, P. A. Introdução à química de alimentos. 3 ed. São Paulo: Varela, 2003. 238 p.

BOBBIO, P. A.; BOBBIO, F. O. Química do processamento de alimentos. 3 ed. São Paulo: Varela, 2001. 143 p.
BRASIL. ANVISA - Agência Nacional de Vigilância Sanitária. Portaria $n^{\circ}$ 27, de 13 de janeiro de 1998. Regulamento Técnico Referente à Informação Nutricional Complementar. Disponível em: <http:// elegis.bvs.br/leisref/public/showAct. php?id=97>. Acesso em: 04 dez. 2007.

DUTCOKSKY, S. D. Análise sensorial de alimentos. Curitiba: Champagnat, 1996. 123p.

FENNEMA, O. R. Química de los alimentos. Zaragoza: Acribia, 1993. p. 275-414.

GOMES, F. P. Estatística aplicada a experimentos agronômicos e florestais. Piracicaba: FEALQ, 2002. 309 p.

GONDIM, J. A. M. et al. Composição centesimal e de minerais em cascas de frutas. Ciência e Tecnologia de Alimentos, v. 25, n. 4 , p. 825-827, 2005.

IAL - INSTITUTO ADOLFO LUTZ. Normas analíticas do Instituto Adolfo Lutz: métodos químicos e físicos de composição dos alimentos. 3 ed. São Paulo: IAL, 1985. v. 1.

JACKIX, M. H. Doces, geléias e frutas em calda. São Paulo: Ícone, 1988. $172 \mathrm{p}$

LAUFENBERG, G.; KUNZ, B.; NYSTROEM, M. Transformation of vegetable waste into value added products: (A) the upgrading concept; (B) practical implementations. Bioresource Technology, v. 87, n. 2, p. 167-198, 2003.

LI, B. W.; CARDOZO, M. S. Nonenzimatic-gravimetric determination of total dietary fiber in fruits and vegetables. Journal AOAC International, v. 75, n. 2, p. 372-374, 1992.

LUNA-GUSMÁN, I.; CANTWELL, M. A.; BARRET, D. M. Fresh-cut cantaloupe: effect of $\mathrm{CaCl}_{2}$ dips and heat treatments on firmness and metabolic activity. Postharvest Biology and Technology, v. 17, n. 3, p. 201-213, 1999.

MORETTI, C. M.; MACHADO, C. M. M. Aproveitamento de resíduos sólidos do processamento mínimo de frutas e hortaliças. 4, 2006, São Pedro. In: ENCONTRO NACIONAL SOBRE PROCESSAMENTO MÍNIMO DE FRUTAS E HORTALIÇAS. Palestras, Resumos, Fluxogramas e Oficinas... Piracicaba: USP/ESALQ, 2006. p. 25-32

PINTO, S. A. A. Processamento mínimo de melão tipo Orange Flesh e de melancia 'Crimson Sweet'. Jaboticabal, 2002. 120 p. Dissertação - (Mestrado em Fitotecnia), Faculdade de Ciências Agrárias e Veterinárias, Universidade Estadual Paulista "Júlio Mesquita Filho".

SCHIEBER, A.; STINTZING, F. C.; CARLE, R. By-products of plant food processing as a source of functional compounds - recent developments. Trends in Food Science \& Technology, v. 12, n. 11, p. 401-413, 2001.

TABELA DE COMPOSIÇÃO DE ALIMENTOS. Disponível em: $<$ http://fapes.net/tabelaalimentos.pdf>. Acesso em: 04 dez. 2007.

THEBAUDIN, J. Y. et al. Dietary fibers: nutritional and technological interest. Trends in Foods Science \& Technology, v. 8, n. 2, p. 41-48, 1997.

USDA. Nutrient Database for Standard Reference. Release 13. US: US Department of Agriculture Research Service, 1999. 